Journal of Research in Interprofessional

Practice and

Education

Vol. 2.2

February, 2012
Journal of Research in Interprofessional Practice and Education (JRIPE)

Vol. 2.2

(c) 2012

Corresponding author: thanhan@@ueensu.cai!

\section{Teaching and Learning Interprofessionally: Family Medicine Residents Differ from Other Healthcare Learners}

\author{
Leslie Flynn, MMus MD CCFP FRCPC; Bethmarie Michalska, M.A.; \\ Han Han, Ph.D.; \& Sangeeta Gupta, M.Sc., BScOT, OT Reg
}

\begin{abstract}
Background: In recent years, interprofessional education and collaborative patientcentred care have been promoted to improve efficiency and quality of healthcare service. Teaching interprofessional education has been challenging. There are few mature curricula, a lack of standardized teaching approaches, and our healthcare learners are educated in different institutional systems. The objective of this study was to explore how one interprofessional educational initiative impacted different healthcare learners from college and university.

Methods and Findings: A day-long interprofessional cognitive behavioural therapy (CBT) workshop was presented to learners from multiple disciplines. Within a framework of collaborative, experiential, and reflective learning, the workshop aimed to promote interprofessional teamwork skills, professional roles, and collaborative behaviours. A mixed-methods design using pre- and post-workshop questionnaires was used to evaluate the effectiveness of the workshop. Significant differences were found between family medicine (FM) residents and healthcare learners of other disciplines in three domains: a) satisfaction with the CBT content area of the workshop, b) attitude toward interprofessional learning and collaboration, and c) the interprofessional learning experience.

Conclusions: The results resonate with longstanding, taken-for-granted roles and attitudes in the culture of healthcare. This study invites serious consideration of when best to embed interprofessional education in healthcare curricula, so that learners will come to shape a professional identity that includes interprofessional collaborative care.
\end{abstract}

Keywords: Interprofessional learning; Collaborative care; Teamwork; Interdisciplinary

\section{Introduction}

Health education has traditionally been silo-based, with each discipline learning its own vocabulary and ways of problem solving, driven by its understanding of the issues $[1,2]$. Although health service requires interprofessional collaboration and teamwork, the current segmentation of knowledge and skills in health education and training systems does not acknowledge this reality [3]. In recent years, Canadian federal and provincial governments have promoted both interprofessional education (IPE) and collaborative patient-centered care to improve the efficiency and quality of healthcare service delivery [1,4,5]. Commissioner Dr. Roy Romanow [5, p.109] appealed to healthcare educators:

In view of ... changing trends, corresponding changes must be made in the way health care providers are educated and trained. If health care providers are expected to work together and share expertise in 
Teaching and Learning Interprofessionally

Flynn, Michalska, Han, \& Gupta

Journal of Research in Interprofessional Practice and Education

Vol. 2.2

February, 2012

\section{Journal of Research in Interprofessional Practice and Education}

a team environment, it makes sense that their education and training should prepare them for this type of working arrangement.

The intention is that through IPE, healthcare providers will acquire the knowledge, skills, and attitudes necessary to collaborate interprofessionally to work together and provide high quality care.

This article reports on one IPE initiative (see Appendix): a day-long cognitive behavioural therapy (CBT) workshop delivered by the Collaborative Interprofessional Team (CIT) at Queen's University in Kingston, Canada, to learners from medicine, psychology, occupational therapy, nursing, theology, and behavioural psychology. The inclusion of these particular professional disciplines fits with what has been identified as necessary for the delivery of effective community mental healthcare [6]. In addition, mental healthcare is being increasingly integrated into collaborative interprofessional primary care [7].

The CIT is an academic mental healthcare team of professionals from psychiatry, psychology, family medicine, occupational therapy, social work, and education. The team was established in 2001 as a clinical team and has been working collaboratively on patient-centred care since then. At the same time, the team members have provided workshops and clinical placements to disseminate the concepts of interprofessional collaboration and improve learners' teamwork competence.

\section{Challenges of teaching and learning IPE}

Teaching IPE has been challenging [3,8]. Such teaching aims to influence learners' attitudes toward interprofessional practice, yet there are few mature curricula or standardized criteria for teaching IPE [9]. Although health curriculum developers have suggested various IPE models [10], many interprofessional educators continue to investigate how best to teach health professionals to work collaboratively [9]. Another challenge arises from health education being delivered in two different systems: universities and community colleges. Although many Canadian healthcare workers are educated in college environments [10], most IPE initiatives have been focused on university learners. Collaborative care can be enhanced by including college-educated learners in IPE alongside their university-based peers. Creating opportunities for learners from both systems to train together will help healthcare professionals appreciate one another's contribution and facilitate collaborative interprofessional care in future practice. Such learning should incorporate at least three elements: 1) assignment of learners to heterogeneous groups, 2) patient-centred focus, and 3) content relevant to the disciplines included in the activity.

\section{Theoretical framework}

Approaches to instilling interprofessional collaboration are still in the exploratory stage [3]. Three strategies for learning provide a theoretical framework for teaching IPE: 1) cooperative learning [11,12], 2) experiential learning [13], and 3) reflective practice [14].

Cooperative learning $(\mathrm{CL})$ is effective for teaching teamwork. It features positive independence, face-to-face interaction, individual accountability, interpersonal and 
Teaching and Learning Interprofessionally

Flynn, Michalska, Han, \& Gupta

Journal of Research in Interprofessional Practice and Education

Vol. 2.2

February, 2012

\section{Journal of Research in Interprofessional Practice and Education}

small-group skills, and group processing [11,12]. Students connect to reach an identified goal, share resources, and have roles that complement one another. They work on a project through discussion, debate, and joint decision-making. Through this learning process, learners develop team skills needed to succeed, analyze both group and individual actions that contribute to team function, and decide how to proceed given this group analysis.

Experiential Learning (EL) has been applied to the practice of adult education, life-long learning, and professional training. In EL, learning is assumed to take place as a result of a planned experiential encounter, where an opportunity to acquire and apply knowledge, skills, and feelings takes place in an immediate, relevant setting. Kolb [13] suggested a four-stage EL framework: planning, doing, observing, and reflecting. Learners plan a response to the situation, and then implement their plan. Through observation and reflection, learners come to create rules and principles and learn from these experiences.

Reflective practice (RP), proposed by Schön [14] is widely applied in professional education. Schön suggested that students be immersed in practice where they can engage in reflection-in-action and reflection-on-action. Reflection-in-action can reshape what students are doing while they are doing it. Reflection-on-action can enable them to look back on experiences and come to an understanding of how outcomes have been achieved. Lachman and Pawlina [15] have added reflection-foraction to further describe reflective practice. Cruess, Cruess, and Steinert discuss reflection-for-action, which "allows for the integration of theoretical concepts into practice; increased learning through experience, enhanced critical thinking and judgment in complex situations; and the encouragement of student-centred learning" [16, p. 35].

CL, EL, and RP theories can contribute to IPE teaching strategies. D'Eon [17] reviewed the IPE models in Canada and found that many had some CL features. Several IPE educators have identified that "reflection is a key component of IPE teaching" [3]. We chose to deliver an integrated educational program using a framework of CL, EL, and RP to learners recruited from different professions and levels of training. Queen's University learners included family medicine (FM) residents, Master of Science students in nursing and occupational therapy (OT), and clinical psychology (CP) students in the master's and doctoral programs. Fourth-year Bachelor of Behavioural Psychology students attended from St. Lawrence College. The primary goals were that students could learn some basics of CBT, acquire teamwork skills, understand professional roles of self and others, and reflect upon behaviours that contribute to collaboration.

\section{Methods}

Based on the positive value of providing an integrated learning opportunity using CL, EL, and RP, a one-day CBT workshop was designed with an interprofessional care focus for healthcare learners. CBT was chosen as the shared content because basic CBT skills are common to the skill sets used by healthcare providers from several disciplines. The workshop objectives were 1) to introduce basic CBT concepts 


\section{JRIPE}

208

Teaching and Learning Interprofessionally

Flynn, Michalska, Han, \& Gupta

and skills and 2) to engage both university and college learners in interprofessional learning and team collaboration. The CIT organized cooperative, experiential, and reflective learning activities through interprofessional simulations and modeled collaborator roles through team teaching.

Learners were recruited from different professions and educational institutions as outlined above. The participants differed in number of years of post-secondary education. The college behavioural psychology (CBP) students had the least, being in their 4th year; the FM residents had the most at approximately 10 years, with the OT, nursing, and $\mathrm{CP}$ students in the middle with 5-8 years. Table 1 describes the sample of participants.

Table 1

Demographics of learners participating in the CBT workshop

\begin{tabular}{|l|l|l|c|}
\hline Discipline & Program & Affiliation & Number \\
\hline Family medicine & Residency program & Queen's University & 40 \\
\hline Occupational therapy & Master's program & Queen's University & 32 \\
\hline Clinical psychology & Master's/doctoral programs & Queen's University & 10 \\
\hline Nursing & Master's program & Queen's University & 3 \\
\hline Theology & Master's program & Queen's University & 1 \\
\hline Behavioural psychology & Bachelor's program & St. Lawrence College & 37 \\
\hline Total & & & 123 \\
\hline
\end{tabular}

Participants were pre-assigned and sorted to learning groups of 7-8 people to maximize multidisciplinary grouping. The basis of sorting was to ensure that each group had participants from family medicine, psychology, occupational therapy, and behavioural psychology. There were few participants from nursing and theology, who were therefore assigned in only some groups as numbers allowed. Thus, learning groups represented different professions, different knowledge bases and skill sets, and different institutions. All groups were engaged in interprofessional learning through case study, group discussion, and collaboration on CBT tasks.

\section{Tasks and team teaching}

Experiential learning activities for interprofessional collaboration included case studies, teamwork games, group discussions, and reflective debriefing. Case study used scenarios often seen in clinical care, so that the learners could draw on their own professional knowledge and skills when working together on a healthcare plan.

Journal of Research in Interprofessional Practice and Education

Vol. 2.2

February, 2012
Basic CBT concepts included automatic thoughts, cognitive distortions, behavioural activation, box breathing, and relaxation training. During activities, interprofessional and teamwork skills of each group were made explicit to learners by CIT monitors. Each activity was followed by a debrief in which the group members reflected on their individual role in the task and their observation of other group 
Teaching and Learning Interprofessionally

Flynn, Michalska, Han, \& Gupta

Journal of Research in Interprofessional Practice and Education

Vol. 2.2

February, 2012

\section{Journal of Research in Interprofessional Practice and Education}

members' roles in the team work. Learners were invited to consider their experience of learning with, from, and about [18,20-22] other disciplines in the group process.

CIT members had consciously planned and prepared the workshop with a view to demonstrate interprofessional behaviours (communication, collaboration, and integration) [23]. At the workshop, they "walked the talk" by ensuring all members showed focused attention to, and active participation in, the ongoing proceedings throughout the workshop; took a turn in the leadership/facilitator role; and harmonized the individual contributions into a collective team voice while role modeling mutual respect and trust. This teaching modeled interprofessional collaborative practice and expertise in mental health. The CIT invited a clinical placement college student to teach relaxation skills as a means of modeling inclusion of a student as a junior team member.

\section{Evaluation}

Research ethics board-approved pre- and post-workshop questionnaires were used to evaluate the effectiveness of the workshop, the learners' IPE learning experience, and their attitudes toward interprofessional collaboration. The pre-workshop questionnaire used open-ended questions to gather information on learners' previous interprofessional learning experiences and knowledge of interprofessional collaboration. The post-workshop questionnaire consisted of a mixed format of closedand open-ended questions and statements with a Likert scale. It was used to collect data on whether or not the workshop met the goals that learners would: 1) grasp basic CBT concepts and their usefulness in counselling techniques, 2) appreciate the roles and contributions of other professionals in healthcare, 3) reflect on the value of learning and practicing with, from, and about one another in healthcare, and 4) consider integrating CBT techniques into their future practice. The questionnaire also solicited learners' comments on the content of learning and approach to teaching, their perception of interprofessional learning, and their attitudes toward interprofessional collaboration.

\section{Data analysis}

The pre-workshop qualitative questionnaire data were collated manually and reported as percentages.

The post-workshop questionnaire statements used a 5-point Likert scale ( strongly disagree $=1$, disagree $=2$, neutral $=3$, agree $=4$, strongly agree $=5$ ). Data were analyzed by item using SPSS (17.0). The data set was dichotomized into "agree" and "disagree" for summary purposes, with "agree" including "strongly agree" and "agree" (4-5), and "disagree" including "strongly disagree," "disagree," and "neutral" (1-3). One-way analysis of variance (ANOVA) was conducted to gain general effects and to identify any differences among the four major groups of learners in the workshop (FM, OT, CP, and CBP). Multiple comparisons were conducted to identify where any between-group differences existed.

Qualitative data from the post-workshop questionnaire were analyzed for recurrent themes. These were used to elucidate the results of the quantitative data analysis. 
210

Teaching and Learning Interprofessionally

Flynn, Michalska, Han, \& Gupta
Journal of Research in Interprofessional

Practice and Education

Vol. 2.2

February, 2012
Table 2

\section{Evaluative description of CBT workshop}

\begin{tabular}{|c|c|c|c|c|c|}
\hline \multirow[t]{2}{*}{ Questionnaire Items } & \multirow[t]{2}{*}{$\begin{array}{c}\text { \% Agree } \\
(N)\end{array}$} & \multirow{2}{*}{$\begin{array}{l}\text { Mean } \\
\text { (Liker } \\
\text { score) }\end{array}$} & \multirow[t]{2}{*}{$\begin{array}{l}\text { Standard } \\
\text { Deviation }\end{array}$} & \multicolumn{2}{|c|}{$\begin{array}{c}\text { One-Way ANOVA } \\
\text { (between FM, OT, CP, } \\
\text { (BP) } d f=3, N=108^{\text {a }}\end{array}$} \\
\hline & & & & $\mathrm{F}$ & $p^{b}$ \\
\hline \multicolumn{6}{|l|}{ The workshop met the following objectives } \\
\hline It described and used basic CBT concepts. & $88 \%(113)$ & 4.12 & 0.71 & 3.50 & *.018 \\
\hline $\begin{array}{l}\text { It demonstrated how CBT techniques might } \\
\text { integrate into my future practice. }\end{array}$ & $59 \%(113)$ & 3.57 & 0.95 & 3.08 & ${ }^{*} .031$ \\
\hline It provided practical strategies using CBT concepts. & $66 \%(113)$ & 3.67 & 0.91 & 1.79 & .154 \\
\hline $\begin{array}{l}\text { It demonstrated the balancing roles of an interprofessional } \\
\text { care team. }\end{array}$ & $51 \%(113)$ & 3.51 & 0.84 & 1.09 & .356 \\
\hline \multicolumn{6}{|l|}{ What did you learn from this workshop? } \\
\hline $\begin{array}{l}\text { I learned the concepts of CBT as a treatment for mental } \\
\text { health problems. }\end{array}$ & $71 \%(113)$ & 3.77 & 0.80 & .38 & .768 \\
\hline I learned some practical CBT techniques. & $75 \%(113)$ & 3.86 & 0.72 & 5.11 & *.002 \\
\hline I experienced learning with peers from other professions. & $86 \%(111)$ & 4.15 & 0.68 & 5.28 & ${ }^{*} .002$ \\
\hline $\begin{array}{l}\text { Group discussions and activities enhance understanding } \\
\text { of CBT and its utility in mental healthcare. }\end{array}$ & $57 \%(111)$ & 3.53 & 0.91 & 1.20 & .314 \\
\hline I appreciate learning with peers of other disciplines. & $90 \%(112)$ & 4.27 & 0.84 & $8.03 *$ & .000 \\
\hline I appreciate the roles of group members in group activities. & $89 \%(112)$ & 4.13 & 0.79 & $4.00 *$ & .010 \\
\hline \multicolumn{6}{|l|}{ The organization of this workshop. } \\
\hline The workshop met my expectations. & $42 \%(110)$ & 3.20 & 1.02 & 2.17 & .096 \\
\hline The speakers presented the information clearly. & $76 \%(112)$ & 3.95 & 0.83 & 1.50 & .220 \\
\hline $\begin{array}{l}\text { The speakers demonstrated the expertise and skills of } \\
\text { CBT in mental healthcare. }\end{array}$ & $73 \%(112)$ & 3.78 & 0.88 & $3.10 *$ & .030 \\
\hline $\begin{array}{l}\text { The speakers demonstrated the balancing roles of an } \\
\text { interprofessional care team presentation. }\end{array}$ & $65 \%(112)$ & 3.61 & 0.88 & 2.60 & .056 \\
\hline
\end{tabular}

Notes: a) Groups compared in the ANOVA and multiple comparisons are as follows: FM-family medicine $(N=32)$, OT-occupational therapy $(N=30),(P$-clinical psychology $(N=10)$, and CBP-college behavioural psychology $(N=36)$. Six subjects did not fit in with any large group, and were excluded as follows: learners who did not identify their discipline $(N=3)$, nursing $(N=2)$, and theology $(N=1)$. b) The mean difference $(p)$ is significant at the 0.05 level. * Indicates significance.

\section{Results}

From the 150 invitations, 133 learners registered and 123 learners attended. Of the 123 questionnaires distributed, 109 pre- and 113 post-workshop questionnaires were returned: response rates, respectively, of $89 \%$ and $92 \%$. The pre-workshop survey showed that $31 \%$ of the learners had "no," and $19 \%$ of the learners had "very lim- 
Teaching and Learning Interprofessionally

Flynn, Michalska, Han, \& Gupta

Journal of Research in Interprofessional Practice and Education

Vol. 2.2

February, 2012

\section{Journal of Research in Interprofessional Practice and Education}

ited" previous experience of interprofessional learning. In the post-workshop survey, 96 learners (90\%) indicated an appreciation of the IPE experience in terms of learning with peers from other disciplines. Ninety-five learners (89\%) appreciated the different roles of their group members in the collaborative learning activities. Ninety-one participants (86\%) reported that they "learned with peers of other disciplines" in the workshop. Most learners indicated that the speakers demonstrated CBT expertise and skills (73\%) and modeled the balanced roles of an interprofessional care team through team teaching (65\%). Group means across the entire set of questionnaire items ranged from 3.20 to 4.27 , indicating the learners' positive views of the workshop. The post-workshop evaluation indicated that the objectives were met (see Table 2).

\section{Differential ratings between the disciplines of learners}

One-way ANOVA was performed on the data of the 4 major disciplines of 108 learners (32 FM residents, 30 OT students, $10 \mathrm{CP}$ university students, and $36 \mathrm{CBP}$ students). Results indicated that significant differences existed among the four disciplines with respect to three aspects:

- satisfaction with the CBT content (basic CBT concepts: $F(3,104)=$ $3.50, p=.018$; practical CBT strategies: $F(3,104)=3.08, p=.031$; CBT techniques: $F(3,104)=5.11, p=.002)$,

- interprofessional learning experience (learning with peers of other disciplines: $F(3,102)=5.28, p=.002)$, and

- attitude toward interprofessional learning and collaboration (appreciate learning with peers of other disciplines: $F(3,103)=8.03$, $p=.000$; appreciate the roles of group members: $F(3,103)=4.00$, $p=.010)$ (see Table 2 above).

The family medicine group had the lowest mean responses to 13 out of 14 items in the questionnaire. Bonferroni tests teased out the nature of the significant differences between family medicine and the other three disciplines (see Table 3).

\section{Differences in satisfaction with the CBT content}

FM residents and OT students differed significantly in their evaluation of how the workshop "described and used the basic concepts of CBT" $(\mathrm{MD}=.49, \alpha=.035)$. The OT students were more satisfied with the teaching of CBT in the workshop. The FM residents also differed from the $\mathrm{CBP}$ learners in responding to the items "[Workshop] demonstrated how CBT techniques might integrate into my future practice" (MD $=-.62, \alpha=.028)$ and "The speakers demonstrated the expertise and skills of CBT in mental health" (MD = -.54, $\alpha=.027$ ). The CBP learners showed more satisfaction with the CBT strategies taught in the workshop than those from FM. As well, the FM participants differed from OT (MD =-.58, $\alpha=.006)$ and Psychology ( $\mathrm{MD}=-.72, \alpha=.027)$, respectively, in response to "I have learned some practical CBT techniques." The latter two groups expressed more satisfaction with the learning of CBT techniques introduced in the workshop (see Table 3). 


\section{JRIPE}

212

Teaching and

Learning

Interprofessionally

Flynn, Michalska, Han, \& Gupta
Table 3

\section{Multiple comparisons (Bonferroni) for identification of differences between disciplines of learners}

\begin{tabular}{|c|c|c|c|c|}
\hline Questionnaire & $\begin{array}{l}1=\mathrm{FM} ; 2=0 \mathrm{~T} ; \\
3=\mathrm{CP} ; 4=\mathrm{CBP}\end{array}$ & $\begin{array}{c}\text { Mean } \\
\text { difference }\end{array}$ & Significance & $\alpha^{\mathrm{a}}$ \\
\hline \multirow[t]{3}{*}{ It described and used the basic concepts of CBT. } & 1 & 2 & -.49 & ${ }^{*} .035$ \\
\hline & & 3 & -.06 & 1.000 \\
\hline & & 4 & -.41 & .096 \\
\hline \multirow[t]{3}{*}{ It provided practical strategies using CBT concepts. } & 1 & 2 & -.37 & .610 \\
\hline & & 3 & -.60 & .370 \\
\hline & & 4 & -.62 & $* 028$ \\
\hline \multirow[t]{3}{*}{$\begin{array}{l}\text { The speakers demonstrated the expertise } \\
\text { and skills of CBT in mental health. }\end{array}$} & 1 & 2 & -.33 & .258 \\
\hline & & 3 & -.77 & .072 \\
\hline & & 4 & -.54 & ${ }^{*} .027$ \\
\hline \multirow[t]{3}{*}{ I learned some practical CBT techniques. } & 1 & 2 & -.58 & $* .006$ \\
\hline & & 3 & -.71 & ${ }^{*} .027$ \\
\hline & & 4 & -.43 & .061 \\
\hline \multirow[t]{3}{*}{$\begin{array}{l}\text { I experienced learning from peers of other } \\
\text { professions. }\end{array}$} & 1 & 2 & -.18 & 1.000 \\
\hline & & 3 & -.45 & .337 \\
\hline & & 4 & -.59 & ${ }^{*} .002$ \\
\hline \multirow[t]{3}{*}{$\begin{array}{l}\text { I appreciate learning with peers of other } \\
\text { disciplines. }\end{array}$} & 1 & 2 & -.72 & ${ }^{*} .002$ \\
\hline & & 3 & -.69 & .091 \\
\hline & & 4 & -.87 & ${ }^{*} .000$ \\
\hline \multirow[t]{3}{*}{$\begin{array}{l}\text { I appreciate the roles that my group } \\
\text { members played in group activities. }\end{array}$} & 1 & 2 & -.38 & .341 \\
\hline & & 3 & -.64 & .134 \\
\hline & & 4 & -.60 & ${ }^{*} .010$ \\
\hline
\end{tabular}

Notes: a) The mean difference $(\alpha)$ is significant at the 0.05 level. ${ }^{*}$ Indicates significance.

\section{Differences in IPE experiential learning}

Journal of Research in Interprofessional Practice and Education

Vol. 2.2

With regard to the IPE learning experience obtained in the workshop, the FM participants differed from the CBP students in their response. The college students responded more favourably to "I experienced learning with peers of other professions" than the FM residents ( $\mathrm{MD}=.60, \alpha=.002)$. 
Teaching and Learning Interprofessionally

Flynn, Michalska, Han, \& Gupta

Journal of Research in Interprofessional Practice and Education

Vol. 2.2

February, 2012
Journal of Research in Interprofessional Practice and Education

\section{Differences in attitude toward interprofessional learning and collaboration}

The FM group showed significant differences in attitudes toward IPE learning and interprofessional collaboration from two other disciplines. In their responses to "I appreciated learning with peers of other disciplines," the FM participants differed from the OT students and the CBP students (MD $=-.87, \alpha=.00$ ), who were more appreciative of interdisciplinary learning. Whereas the CBP students showed the most appreciation of multidisciplinary learning, those from FM showed the least. In response to the degree of appreciation of the "roles that the group members played in group activities," the FM participants also showed less appreciation than the CBP students (MD $=-.60, \alpha=.01$ ).

\section{Responses to open-ended questions}

Qualitative responses indicated that the FM group had different expectations for specific content and skills of CBT than other disciplines. Some FM residents expressed their disappointment with the workshop. They suggested that teaching should involve "more clinical application of the techniques," and that the content should be about "anti-depressant, anti-psychotics that I will be prescribing." Some thought that CBT was "not for family medicine." By contrast, the students from other disciplines, who indicated that they had previously learned CBT, had an overall positive view of the learning.

Most learners in the workshop reported that interprofessional team collaboration was "important," "vital," "essential," "effective," "holistic," and "valuable" in primary or mental healthcare. For example, one college student said, "Today's conference was great as there were many disciplines at the table to discuss a case study. Hearing different perspectives was very interesting and eye-opening." The FM residents expressed some doubts. For example, they were "not clear about professional roles in real world," they had "no time to spend on one patient [in team work]," and they questioned "communication in an effective interprofessional collaborative model." When asked if they would include interprofessional team care in their future practice, the participants overall expressed willingness to work in interdisciplinary teams or work with other professionals. Some FM participants understood this as "working in a Family Health Team" or as "referring [clients] to the psychologist" for counselling.

\section{Discussion}

This IPE-oriented workshop met the objectives of successfully providing an interprofessional learning experience, organizing interdisciplinary collaboration among learners from multiple disciplines, and teaching basic CBT concepts and techniques. We believe that the teaching approaches used (cooperative learning, experiential learning, and reflective practice) contributed to this success.

The workshop evaluation results revealed different expectations of the learning content, different perceptions of the learning experience, and different attitudes with respect to interprofessional collaboration. Primarily, the differences existed 
214

Teaching and Learning Interprofessionally

Flynn, Michalska, Han, \& Gupta

Journal of Research in Interprofessional Practice and Education

Vol. 2.2

February, 2012 between the FM residents and those from the other disciplines (OT, CP, and CBP). Gilbert points out that healthcare professional identity is forged in academic programs and curricula, disciplinary culture, scope of practice, competencies, and responsibilities claimed by professions and specializations. Such professional identity is passed from generation to generation "through the highly ritualized institutions of medical education" [19, as cited in 18, p. 91]. Healthcare learners acquire this identity in their academic programs. It is reinforced through practice criteria, responsibility assigned to each profession, and external accreditation processes. Hall [24] amplifies Schroeder et al.s [25] discussion (1999) of the existence of distinct disciplinary cultures within each healthcare profession. While disciplinary culture and professional identity help healthcare learners shape their practice behaviours and define their professional roles, they also reinforce historical relationships, including barriers.

The noted differences in our study between physicians and their future colleagues from allied health illustrate the longstanding, taken-for-granted roles and attitudes that exist in the culture of healthcare [26]. The learners from FM reported less satisfaction with the CBT content than the others present, and less appreciation of learning with their peers from other disciplines. In terms of the content, the FM residents had not had as much prior exposure to CBT techniques as the learners from OT, clinical psychology, and behavioural psychology. They might see CBT as "less core" in terms of required learning. Some residents' comments included a desire for education about mainstream tools such as pharmacotherapy. "Talking therapy" did not appear to have as much relevance to them.

Their lessened appreciation of interprofessional learning might relate to the level of "advanced specialization" of family medicine [18]. Having a previously established understanding of their roles and relations with other professionals in healthcare, the residents did not place priority on the new role of collaborator in an interdisciplinary setting [26]. Given the present imperative for interprofessional collaboration and care, we must consider the implications of the differences between the FM residents and the allied healthcare learners for future healthcare service delivery.

Disciplinary culture, language, and communication might be modified through an IPE approach. First, IPE curricula can focus on common content areas such as CBT that can be taught to various healthcare disciplines, bringing them to "learn together." This process benefits them by expanding their knowledge base and exposing them to new skills across their specific disciplines. Second, an IPE design can set up a forum where learners from multiple disciplines interact. This interactive learning process provides opportunities for multidisciplinary learners to collaborate on tasks, explore solutions from different perspectives, and reflect on professional roles, so that they learn with, from, and about [18,20-22] each other. While the content area serves as a vehicle for multidisciplinary learning, it is the IPE-oriented approach that transforms learning together into a collaborative, interprofessional experience.

Although this workshop enhanced students' knowledge and concepts of interprofessional collaboration, it was insufficient to shift the FM residents' beliefs about 
Teaching and Learning Interprofessionally

Flynn, Michalska, Han, \& Gupta

Journal of Research in Interprofessional Practice and Education

Vol. 2.2

February, 2012

\section{Journal of Research in Interprofessional Practice and Education}

their roles and attitudes toward other professions. It is likely that a one-day IPE-oriented workshop is inadequate for learners to fully experience collaborative teamwork and develop collaborative strategies; nevertheless, it allowed them to "sample" an interprofessional teamwork experience. Did this IPE experience come too late in the educational process for the physicians? Perhaps their professional identity was already so firmly entrenched through their many years of post-secondary education and their subsequent medical training that the FM residents were less inclined to integrate this experience and its potential benefit for their future working lives.

Health Canada has recommended moving IPE for collaborative patient-centred practice forward [20]. The Romanow Report [5] recommends that IPE is essential for preparing healthcare professionals for the future. By embedding IPE components in healthcare programs and curricula, particularly in the approaches to delivering teaching and learning [20], in practice criteria, and external accreditation, it can be expected that healthcare learners will come to shape new professional identities that include interprofessional learning and collaborative care. This system-wide change is in progress nationally [27] and world-wide [28]. Serious consideration of when best to embed this educational approach continues to be an empirical issue $[3,7,8,21]$. We support the assumption made by the Canadian Interprofessional Health Collaborative (CIHC) Interprofessional Competency Framework that "the level of interprofessional competence demonstrated is dependent on the depth and breadth of opportunities for education and practice experience with, from and about other health providers" [27, p.9]. Family physicians will work closely with allied professionals in the new model of care established as Family Health Teams. It is essential that the identity forged by these physicians does not limit their ability to appreciate the value of learning with, from, and about [18,20-22] their healthcare colleagues from other disciplines. Our results suggest that the introduction of the IPE experience at a later stage may not be as effective as desired. We recommend the introduction of IPE at an earlier stage of education with multiple exposures in order to ensure a culture of learning and practice that is optimally collaborative.

One limitation of this study is the imbalance in the number of participants from the varied disciplines. The makeup of each group and the dynamics of the interactions would be influenced by this discrepancy. A second limitation is that the intervention was a one-day IPE experience, lacking the opportunity for subsequent follow-up with the participants. The ability to assess the impact of the IPE experience on learner attitudes and clinical practice would be beneficial. Future research may look at IPE strategies implemented at an earlier stage of education, with followup, to consider the efficacy for influencing later behaviour.

\section{Abbreviations}

$\mathrm{IPE}=$ interprofessional education

$\mathrm{CBT}=$ cognitive-behavioural therapy

$\mathrm{CL}=$ cooperative learning

$\mathrm{EL}=$ experiential learning

$\mathrm{RP}=$ reflective practice 
216

Teaching and Learning Interprofessionally

Flynn, Michalska, Han, \& Gupta

Journal of Research in Interprofessional Practice and Education

Vol. 2.2

February, 2012

\author{
$\mathrm{FM}=$ family medicine \\ OT = occupational therapy \\ $\mathrm{CP}=$ clinical psychology \\ $\mathrm{CBP}=$ college behavioural psychology
}

\section{References}

1. Gilbert, J.H.V., Burton, A., \& Sawatzky-Girling, B. (2008). Situational analysis: Current state of interprofessional education in_Canada._Vancouver, BC._Canadian_Interprofessional_Health,

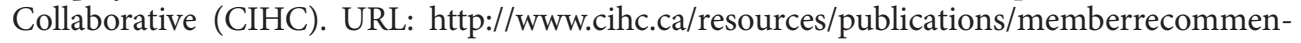
'deded'[July 15, 2009].

2. Gurran, V., Sargeant, J., \& Hollett, A. (2007). Evaluation of an interprofessional continuing professional development initiative in health care. Journal of Continuing Education in the Health Profession, 27, 241-52.

3. Oandasan, I., \& Reeves, S. (2005). Key elements for interprofessional education. Part 1: The learner, the educator and the learning context. Journal of Interprofessional Care, 19(S1), 21-38.

4. HealthForceOntario. (2007). Interprofessional_care:_A_blueprint_for_action_in_ontario.

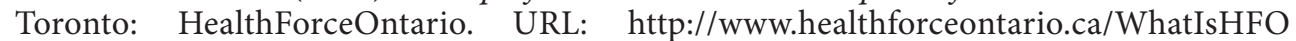

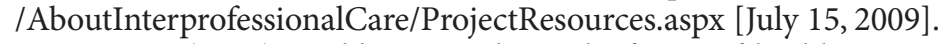

5. Romanow, R.J. (2002). Building on values: The future of health care in Canada. Saskatoon (SK): Commission on the Future of Health Care in Canada.

6. Malone, D., Marriott, S., Newton-Howes, G., Simmonds, S., \& Tyrer, P. (2007). Community mental health teams (CMHTs) for people with severe mental illnesses and disordered personality. Cochrane Database System Review, 4, CD000270.

7. Lester, H., \& Glasby, J. (2004). Integrated primary mental health care: Threat or opportunity in the new NHS? British Journal of General Practice, 54(501), 285-91.

8. Freeth, D. (2007). Interprofessional education. Edinburgh (UK): Association for the Study of Medical Education.

9. Soklaridis, S., Oandasan, I., \& Kimpton, S. (2007). Family health teams: Can health professionals learn to work together? Canadian Family Physician, 53, 1198-99.

10. Cook, D.A. (2005). Models of interprofessional learning in Canada. Journal of Interprofessional Care, 19(S1), 107-15.

11. Johnson, D.W., Johnson, R.T., \& Smith, K.A. (1998). Cooperative learning returns to college: What evidence is there that it works? Change, 30(4), 26-35.

12. Nilson, L.B. (1998). Teaching at its best: A research-based resource for college instructors. Jaffrey (NH): Anker Publishing Company.

13. Kolb, D.A. (1984). Experiential learning. Englewood Cliffs (NJ): Prentice-Hall.

14. Schön, D. (1983). The reflective practitioner: How professionals think in action. New York: Basic Books.

15. Lachman, N., \& Pawlina, W. (2006). Integrating professionalism in early medical education: the Theory and application of reflective practice in the anatomy curriculum. Clinical Anatomy, 19(5), 456-60.

16. Cruess, R.L., Cruess, S., \& Steinert, Y. (2009). Teaching medical professionalism. New York: Cambridge University Press.

17. D’Eon, M. (2004). A blueprint for interprofessional learning. Medical Teacher, 26(7), 604-609.

18. Gilbert, J.H.V. (2005). Interprofessional learning and higher education structural barriers. Journal of Interprofessional Care, 19(S1), 87-106.

19. Fleischman, S. (2001). Language and medicine. In D. Schriffin, D. Tannen, \& H. Hamilton (Eds.), The handbook of discourse analysis (pp. 470-502). Oxford: Blackwell.

20. Health Canada. (2006). Interprofessinal_education_for_collaborative patient-centered_practice.

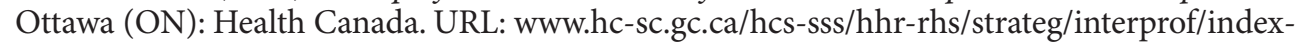
'eng.php.' [November 20, 2009].

21. Barr, H., Koppel, I., Reeves, S., Hammick, M., \& Freeth, D. (2005). Effective interprofessional education. Oxford (UK): Blackwell Publishing.

22. Barr, H. (2001). Interprofessional education - today, yesterday and tomorrow. London (UK): Centre for the Advancement of Interprofessional Education (CAIPE).

23. Martin, V., \& Rogers, A. (2004). Leading interprofessional teams in health and social care. New York: Routledge. 


\section{JRIPE \\ Journal of Research in Interprofessional Practice and Education}

217

Teaching and

Learning

Interprofessionally

Flynn, Michalska, Han, \& Gupta
24. Hall, P. (2005). Interprofessional teamwork: Professional cultures as barriers. Journal of Interprofessional Care, 19(S1), 188-96.

25. Schroeder, R.E., Morrison, E.E., Cavanaugh, C., West, M.P., \& Fache, J.M. (1999). Improving communication among health professionals through education: A pilot study. Journal of Health Administration Education, 17, 175-98.

26. Horsburgh, M., Perkins, R., Coyle, B., \& Degeling, P. (2006). The professional subcultures of students entering medicine, nursing and pharmacy programmes. Journal of Interprofessional Care, 20(4), 425-31.

27. Canadian Interprofessional Health Collaborative. (2010). A national interprofessional competency framework _ Vancouver:_Canadian _ Interprofessional_Health Collaborative. URL: Ihttp://I!

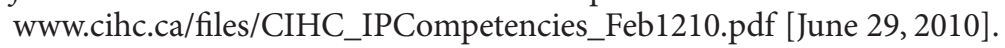

28. World Health Organization. (2010). Framework for action on interprofessional education and collaborative practice (WHO/HRH/HPN/103). Geneva: World Health Organization. URL: 'http://wwww.who.int/hrh/nursing_midwifery/en/_! [June 29, 2010]. 


\section{JRIPE}

218

Teaching and

Learning

Interprofessionally

Flynn, Michalska, Han, \& Gupta

Journal of Research in Interprofessional Practice and Education

Vol. 2.2

February, 2012
Journal of Research in Interprofessional Practice and Education

\section{Appendix}

This appendix is provided to illustrate the use of the CBT model as common content knowledge, which provided the foundation for the cooperative, experiential, and reflective learning opportunities incorporated into the IPE experience.

\section{Basic CBT model}

- Concepts: thoughts, feelings, body, and behaviour

- Relationships

\section{Objectives}

- Learn to identify how thoughts, feelings, body, behaviour interact with each other and influence a person's mood, attitude, and emotion

\section{Case study}

Adam is a 38 year old who has a wife and two children (aged 2 and 5). He is seeking care. He comes today because he just can't manage anymore. He has had disrupted sleep for four weeks. He is a grade 10 English teacher and is under a lot of pressure to prepare his students for the grade 10 literacy testing next month.

His wife Jill works shifts at a call centre. After years of working casual, she finally got a full time position that was straight nights. They had both thought this was great. Now their money worries were over and their work schedules would allow them to split the childcare so they could make sure their children were well looked after.

But now it feels like a disaster. Jill is always either sleeping or tired. They argue all the time about who is paying the bills, doing the chores, and about how to raise the kids. She expects him to do everything now that she's working. It's not that he minds doing his share but her constant criticism of how he's doing things makes him angry and resentful. It used to be that he participated in a lot of sports but he had to give that up. There is just no time and his old knee injury is acting up. Recently he was asked to coach hockey again, but there was no way!

Adam and Jill are at the end of their rope. He says something has to change or one of them will snap!

\section{Group project}

1. Read the case

2. Individual work - identify the top 2 priority issues in this case

3. Share your ideas with the table

4. Small group sharing: Reflect on the process of sharing your priorities in an interprofessional group.

- Was there anything that surprised you about the identified priorities?

- Was there a common priority among all professions?

- Was there an obvious discrepancy in priorities?

- What professions identified similar priorities?

- What professions identified different priorities?

5. Large group sharing 